\title{
The Lipid and Resin Composition of Laretia compacta Phil. from the Andes of Chile
}

\author{
Bernd R. T. Simoneit ${ }^{\mathrm{a}}$ and Borys M. Didyk ${ }^{\mathrm{b}}$ \\ ${ }^{a}$ Petroleum and Environmental Geochemistry Group, College of Oceanic and Atmospheric \\ Sciences, Oregon State University, Corvallis, OR 97331, U. S. A. \\ ${ }^{b}$ Refineria del Petroleo, S. A., Concon, Chile \\ Z. Naturforsch. 54c, 309-313 (1999); received October 7, 1998/February 9, 1999 \\ Laretia, Resin, Sesquiterpenoids, Kaurene and Phyllocladene Diterpenoids, Phytosterols \\ The lipid/resin components of Laretia compacta were characterized by GC-MS and CSIA. \\ The lipid components consist of $n$-alkanes, $n$-alkanoic acids and $n$-alkanols all with low car- \\ bon number maxima and high CPI values. The resin components are comprised of major \\ amounts of tetracyclic diterpenoids with a minor content of mono- and sesquiterpenoids. The \\ kaurene skeleton predominates with some phyllocladenes. Phytosterols are trace compo- \\ nents. The $\delta^{13} \mathrm{C}$ data of the individual alkanes in the hydrocarbon fraction place this species \\ in the $\mathrm{C}_{4}$ plant group.
}

\section{Introduction}

Natural products or their derivatives are used by organic geochemists as tracers for environmental processes (e.g. Johns, 1986; Simoneit, 1978; 1989; Simoneit and Mazurek, 1982). Remote locales in South America are ideal sites as pristine references for background studies. Laguna Lejia, one such study area, is located on the Altiplano of the Andes in Antafogasta, Chile. We encountered biomarker derivatives from resin acids with higher plant wax lipids and inferred that these compounds were brought in by atmospheric fallout to the lake (Simoneit et al., 1980). The region is barren of trees, especially gymnosperms which produce resins, and potential sources such as the Araucariaceae grow far to the south (Muñoz, 1966).

We noted that dry Laretia compacta Phil. (family - Umbellifereae, common name Llareta) was being used as kindling in the hotel of San Pedro de Atacama. This material had a strong resinous odor, which is intriguing with regards to a possible source for resin compounds in the Altiplano environment. The plant grows as dense pillow-like structures of $5-100 \mathrm{~cm}$ thickness and up to $3 \mathrm{~m}$ diameter. It is composed of a compact mass of

Reprint requests to Prof. B. R. T. Simoneit.

Fax: 541-737-2064

E-mail: simoneit@oce.orst.edu stems, branches and dry leaves under a growth canopy of light green leaves (Suárez Contreras, 1935; Wickens, 1995). Laretia sp. is found in the Andes at high altitudes $(>3000 \mathrm{~m})$ in the northern ranges of Chile and also at lower altitudes in the southern area around $35^{\circ} \mathrm{S}$. The growth rate, under the harsh Andean environmental conditions, is 1.5 to $5 \mathrm{~mm}$ per year (Suárez Contreras, 1935).

In the wood depleted area of its natural habitat, Laretia sp. has been used historically in large volumes as firewood and cooking fuel by local cultures, and later, in early industrial and mining activities, as a fuel source which has contributed to its present scarcity. The plant and its resin exudates were used by Andean cultures for medicinal purposes and presently hot water infusions are used as herbal medicine for various ailments (Suárez Contreras, 1935; Wickens, 1995). We are not aware of any chemical studies on this resin and therefore obtained a specimen of Laretia sp. for molecular characterization of the lipid-resin extract.

\section{Experimental}

Sample

A piece of stem with branches and leaves was sampled from a dried specimen of Laretia compacta. It had been collected in the mountains near San Pedro de Atacama, Chile. The material (2 g) was crushed in a mortar and pestle and extracted 
in a Soxhlet apparatus with a chloroform/methanol mixture $(4: 1, \mathrm{v} / \mathrm{v})$ for about 300 siphon cycles. The extract $(480 \mathrm{mg})$ was concentrated to about $1 \mathrm{ml}$ on a rotary evaporator, treated with diazomethane to derivatize labile functional groups and sequentially concentrated under nitrogen blowdown.

\section{Lipid separation}

The extract was separated by thin layer chromatography (TLC) on silica gel G plates (duplicate) which had been cleaned prior to use with repetitive solvent elutions and were activated at $120^{\circ} \mathrm{C}$ for $20 \mathrm{~min}$. After application of the extract and elution standards the TLC plates were developed with a mixture of heptane and ether $(9: 1 \mathrm{v} / \mathrm{v})$. Examination under UV revealed no fluorescence. The dried plates were then exposed to iodine vapor to visualize the bands and the following portions were scraped off: F1 $\left(R_{\mathrm{f}} 1.00-0.77\right.$, hydrocarbons), F2 ( $R_{\mathrm{f}} 0.77-0.54$, monoaromatics, esters, ethers), F3 $\left(R_{\mathrm{f}} 0.54-0.32\right.$, aromatics $), \mathrm{F} 4\left(R_{\mathrm{f}} 0.32-\right.$ 0.06 , polars $)$, and F5 ( $R_{\mathrm{f}} 0.06-0.00$, origin). The fractions were eluted with heptane or ethyl acetate depending on polarity. Fractions 1-3 were analyzed by gas chromatography (GC) and GC-mass spectrometry (MS) without further derivatization. Fraction 4 was analyzed after derivatization with silylating reagent by GC-MS.

\section{Instrumental analyses}

$\mathrm{GC}$ analyses of the lipid fractions were performed with a Hewlett Packard 5890A instrument, equipped with a $30 \mathrm{~m} \times 0.25 \mathrm{~mm}$ i.d. DB- 1 open tubular column $(0.25 \mu \mathrm{m}$ film thickness). The GC oven was heated using the following program: isothermal for $2 \mathrm{~min}$ at $65^{\circ} \mathrm{C}, 3^{\circ} / \mathrm{min}$ to $310^{\circ} \mathrm{C}$, and isothermal for $30 \mathrm{~min}$, with the injector at $290^{\circ} \mathrm{C}$, detector at $325^{\circ} \mathrm{C}$, and helium as the carrier gas.

GC-MS was performed on a Finnigan 9610 gas chromatograph coupled to a Finnigan 4021 quadrupole mass spectrometer operated at $70 \mathrm{eV}$ over the mass range 50-650 dalton and a cycle time of $2.0 \mathrm{~s}$. The GC had the same column as above and the oven temperature was programmed at isothermal for 2 min at $65^{\circ} \mathrm{C}, 4^{\circ} / \mathrm{min}$ to $310^{\circ} \mathrm{C}$, and isothermal for $30 \mathrm{~min}$, with the injector at $290^{\circ} \mathrm{C}$, and helium as the carrier gas. The MS data were ac- quired and processed with an on-line FinniganIncos 2300 computer data system.

Compounds were identified by comparison with authentic standards, matching library mass spectra, or interpretation of the MS fragmentation pattern.

\section{Stable carbon isotope analyses}

Compound Specific Isotope Analyses (CSIA) by online gas chromatography-isotope ratio mass spectrometry were conducted on the aliphatic hydrocarbon fraction. The CSIA were performed on a modified version of a Finnigan GC-C-MS system (Hayes et al., 1990; Freeman, 1991; Schoell et al., 1992). The data system at that time was ISODAT version 4.0. In the system used here the gas flow and the combustion interface were completely rebuilt for better resolution of complex mixtures with closely eluting peaks (Schoell et al., 1992; Simoneit et al., 1993). The oven was a quartz capillary of $0.1 \mathrm{~mm}$ i.d. with a cupric oxide wire insert and uses a combustion temperature of $850{ }^{\circ} \mathrm{C}$. The GC conditions were as follows: Column, HewlettPackard Ultra $1(50 \mathrm{~m} \times 0.32 \mathrm{~mm}$ i.d., $0.5 \mu \mathrm{m}$ stationary phase, cross linked methyl silicone); carrier gas, helium $(1.5 \mathrm{ml} / \mathrm{min})$; temperature program, $3 \% \mathrm{~min}$ from $60^{\circ}$ to $320^{\circ}$ and 20 minutes isothermal hold. $\mathrm{CO}_{2}$ injected during analysis through the change over valve of the mass spec-

Table I. Yields of lipid fractions, homologous series and biomarkers from Laretia compacta.

\begin{tabular}{lclll}
\hline Fraction & Yield* $[\mu \mathrm{g} / \mathrm{g}]$ & $\mathrm{C}$ range & $\mathrm{CPI}^{+}$ & $\mathrm{C}_{\max }$ \\
\hline Total extract & $240,000(24 \%)$ & & & \\
F1, Hydrocarbons & 22,400 & & & \\
$\quad$-Alkanes & 370 & $19-31$ & 9.7 & 23 \\
$\quad$ Terpenes & 12,000 & $10,15,20$ & & 20 \\
F2\&3, Polar com- & 17,800 & & & \\
pounds & & & & \\
$\quad$-Alkanoic acids & 3,600 & $12-26$ & 18.9 & $\mathbf{1 6}, 22$ \\
$\quad$ Terpenoids & 13,100 & 20 & & 20 \\
F4, Alcohols & 2,700 & & & \\
$\quad n$-Alkanols & 150 & $16-32$ & 21.5 & $\mathbf{2 2 , 2}$ \\
$\quad$ Diterpenoids & 2,580 & 20 & & 20 \\
$\quad$ Phytosterols & 42 & 28,29 & & 29 \\
\hline
\end{tabular}

* Based on microgram per gram of dry weight of the plant material.

+ Carbon preference index, expressed as $\Sigma$ odd $/ \Sigma$ even homologs for $n$-alkanes and $\Sigma$ even $/ \Sigma$ odd for $n$-alkanoic acids and $n$-alkanols. 
trometer with or without sample background was used as reference standard. The carbon isotopic compositions of individual compounds were calculated relative to the $\mathrm{CO}_{2}$ standard and are reported in the usual delta notation versus the PDB (Pee Dee Belemnite) standard. The reproducibilities for 3 repeat analyses range from 0.4 and 1.6\%.

\section{Results and Discussion}

The fraction and compound class yields are high based on dry weight of the whole plant, where $24 \%$ is extractable and can be identified as $4160 \mu \mathrm{g} / \mathrm{g}(0.4 \%)$ lipids and $2.8 \%$ terpenoids (Table I). The lipids are comprised of $\mathrm{C}_{19}-\mathrm{C}_{31}$ $n$-alkanes $\left(\mathrm{C}_{\max }=23, \mathrm{CPI}=9.7\right), \mathrm{C}_{12}-\mathrm{C}_{26} n$-alkanoic acids $\left(\mathrm{C}_{\max }=16, \mathrm{CPI}=18.9\right), \mathrm{C}_{16}-\mathrm{C}_{32} n$-alkanols $\left(\mathrm{C}_{\max }=22>28, \mathrm{CPI}=21.5\right)$, and minor phytosterols (Table I). Overview plots of the homologous series are shown in Fig. 1. The major terpenoids identified are listed in Table II and consist of mono-, sesqui- and diterpenoids. No triterpenoids were detectable and the phytosterols consisted of only $\beta$-sitosterol and stigmasterol.

The monoterpenoids consist primarily of bornyl acetate, $\alpha$-terpinene and fenchone. The sesquiterpenoids comprise the hydrocarbons alloaromadendrene, aromadendrene, 8,9-didehydrocycloisolongifolene, neoclovene and a guaiene and the methyl ethers of bulnesol and two other sesquiterpenols. The tetracyclic diterpenoids are the dominant resin biomarkers. The kaurene skeleton is the major structure as the hydrocarbon and hydroxy, keto and acid derivatives, with the phyllocladene skeleton as a minor contributor. Tricyclic diterpenoids (e.g., abietene or pimarane skeletons) are not detectable. However, the tetracyclic diterpenoids can alter to tricyclic derivatives by diagenetic or thermal processes (e.g., Grimalt et al., 1990).

The hydrocarbon fraction was also analyzed by CSIA for the ${ }^{13} \mathrm{C} /{ }^{12} \mathrm{C}$ composition of each major compound (Table III). Such data can be utilized to distinguish plants with the different carbon fixation pathways (e.g., Smith and Epstein, 1971; Collister et al., 1994) and as complimentary molecular data for correlation with the chemical structures of natural products (e.g., Simoneit et al., 1993). The $n$-alkanes have a mean $\delta^{13} \mathrm{C}=-19.5 \%$ typical for $\mathrm{C}_{4}$ plants (i.e., the dicarboxylic acid or Hatch-Slack cycle, with a $\delta^{13} \mathrm{C}$ range of -18 to $-25 \%$ ) (Smith and Epstein, 1971; Collister et al., 1994). Thus, we assign Laretia compacta to the $\mathrm{C}_{4}$ plant group. The tetracyclic diterpenes have a mean $\delta^{13} \mathrm{C}=-24.6 \%$, distinctly different from the $n$-alkanes. This carbon isotope composition is typical as observed for diterpenoids from contemporary conifers of the northern hemisphere and fossil resins and ambers. The biosynthesis of isoprenoids introduces a different carbon isotope signature into the products than lipid synthesis of aliphatic compounds.

\section{Conclusion}

The lipids of Laretia compacta consist of $n$-alkanes, $n$-alkanoic acids and $n$-alkanols, all with low carbon number maxima. The resin consists of mainly tetracyclic diterpenoids (kaurenes and
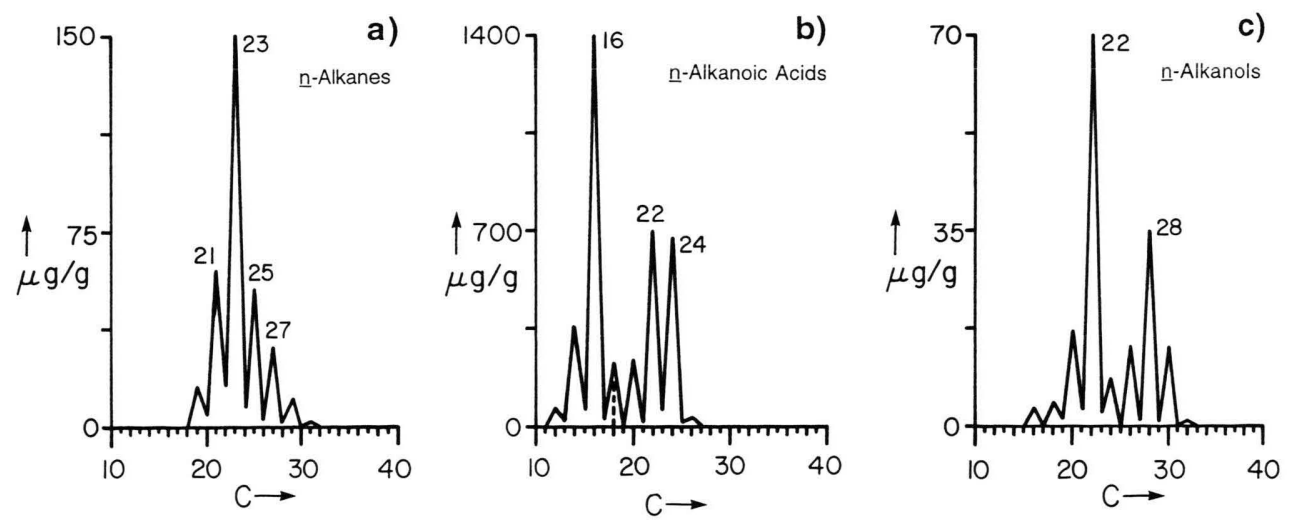

Fig. 1. Distribution diagrams of concentration vs. carbon number for the homologous lipid components of Laretia compacta: (a) $n$-Alkanes, (b) $n$-alkanoic acids (dashed line $=$ octadecenoic acids), (c) $n$-alkanols. 
Table II. Resin biomarkers of Laretia compacta.

\begin{tabular}{|c|c|c|c|c|}
\hline Compound name* & Composition & Yield $[\mu \mathrm{g} / \mathrm{g}]^{+}$ & $\mathrm{MW}^{\ddagger}$ & Key ions in $\mathrm{MS}^{\ddagger}$ \\
\hline Dimethylstyrene (S) & $\mathrm{C}_{10} \mathrm{H}_{12}$ & 60 & $132(100)$ & $65(45), 91(52), 117(90)$ \\
\hline$\alpha$-Terpinene (S) & $\mathrm{C}_{10} \mathrm{H}_{16}$ & 185 & $136 \quad(18)$ & 72 (100), 93 (15), 121 (9) \\
\hline Fenchone (S) & $\mathrm{C}_{10} \mathrm{H}_{18} \mathrm{O}$ & 120 & 154 (18) & $\begin{array}{l}55(100), 71(95), 111(60) \\
125(22), 139(8)\end{array}$ \\
\hline Bornyl acetate $(S)$ & $\mathrm{C}_{12} \mathrm{H}_{20} \mathrm{O}_{2}$ & 270 & $196 \quad(3)$ & $\begin{array}{l}93(50), 95(100), 121(27), \\
136(30), 154(6)\end{array}$ \\
\hline$\gamma$-Guaiene (I) & $\mathrm{C}_{15} \mathrm{H}_{24}$ & 35 & $204 \quad(45)$ & $\begin{array}{l}91(50), 105(50), 119(70) \\
147(100), 162(75), 189(6)\end{array}$ \\
\hline Alloaromadendrene (S) & $\mathrm{C}_{15} \mathrm{H}_{24}$ & 150 & $204 \quad(30)$ & $\begin{array}{l}55(95), 93(100), 105(90) \\
107(88), 119(60), 135(35) \\
161(55), 175(13), 189(24)\end{array}$ \\
\hline Aromadendrene (S) & $\mathrm{C}_{15} \mathrm{H}_{24}$ & 90 & $204 \quad(28)$ & $\begin{array}{l}55(90), 79(100), 93(85), 107(83), \\
119(55), 133(40), 161(50), \\
175(10), 189(65)\end{array}$ \\
\hline Neoclovene (S) & $\mathrm{C}_{15} \mathrm{H}_{24}$ & 40 & $204 \quad(58)$ & $\begin{array}{l}55(57), 91(65), 105(98), 119(42) \\
133(45), 161(42), 189(100)\end{array}$ \\
\hline $\begin{array}{l}\text { 8,9-Didehydrocyclo- } \\
\text { isolongifolene (S) }\end{array}$ & $\mathrm{C}_{15} \mathrm{H}_{22}$ & 140 & $202(85)$ & $\begin{array}{l}69(80), 105(60), 131(70), 145(40), \\
159(100), 187(43)\end{array}$ \\
\hline $\begin{array}{l}\text { Sesquiterpenol methyl } \\
\text { ether (I) }\end{array}$ & $\mathrm{C}_{16} \mathrm{H}_{28} \mathrm{O}$ & 220 & $236 \quad(45)$ & $\begin{array}{l}55(100), 93(85), 105(80), 135(60), \\
161(58), 163(50), 189(10), 204(8)\end{array}$ \\
\hline $\begin{array}{l}\text { Sesquiterpenol methyl } \\
\text { ether (I) }\end{array}$ & $\mathrm{C}_{16} \mathrm{H}_{28} \mathrm{O}$ & 540 & $236 \quad(1)$ & $\begin{array}{l}125 \text { (100), } 161(7), 193(19), 204 \text { (3), } \\
221 \text { (4) }\end{array}$ \\
\hline Bulnesol methyl ether (I) & $\mathrm{C}_{16} \mathrm{H}_{28} \mathrm{O}$ & 742 & $236 \quad(1)$ & 73 (100), 107 (5), 163 (3), 204 (2) \\
\hline Phyllocladadiene (I) & $\mathrm{C}_{20} \mathrm{H}_{30}$ & 135 & $270(100)$ & $\begin{array}{l}55(88), 105(70), 131(80), 227(65), \\
255(45)\end{array}$ \\
\hline Phyllocladene (S) & $\mathrm{C}_{20} \mathrm{H}_{32}$ & 310 & $272 \quad(55)$ & $\begin{array}{l}55(95), 105(75), 191(40) \\
229(100), 275(30)\end{array}$ \\
\hline Kaur-16-ene (S) & $\mathrm{C}_{20} \mathrm{H}_{32}$ & 6640 & $272 \quad(55)$ & $\begin{array}{l}55(100), 91(55), 105(53), 119(51), \\
187(30), 229(25), 243(10), 257(35)\end{array}$ \\
\hline Hibaene $(\mathrm{S})$ & $\mathrm{C}_{20} \mathrm{H}_{32}$ & 1140 & $272(70)$ & $\begin{array}{l}55(100), 105(70), 161(50), \\
187(35), 229(35), 243(30), 257(35)\end{array}$ \\
\hline Tetracyclic diterpene & $\mathrm{C}_{20} \mathrm{H}_{32}$ & 1200 & $272(48)$ & $\begin{array}{l}55(100), 108(72), 119(65) \\
229(50), 257(25)\end{array}$ \\
\hline Methoxykaurene (I) & $\mathrm{C}_{21} \mathrm{H}_{34} \mathrm{O}$ & 200 & $302 \quad(15)$ & $\begin{array}{l}55(100), 99(75), 257(55), 270(18), \\
287(9)\end{array}$ \\
\hline Methoxykaurane (I) & $\mathrm{C}_{21} \mathrm{H}_{36} \mathrm{O}$ & 7080 & 304 (14) & $\begin{array}{l}55(100), 229(30), 243(14) \\
257(33), 272(30), 289(3)\end{array}$ \\
\hline Methyl ketokaurenoate(I) & $\mathrm{C}_{21} \mathrm{H}_{30} \mathrm{O}_{3}$ & 1520 & $330 \quad(18)$ & $\begin{array}{l}93(100), 105(80), 132(50) \\
227(28), 257(30), 270(14)\end{array}$ \\
\hline Kaurenoic acid - TMS (I) & $\mathrm{C}_{23} \mathrm{H}_{38} \mathrm{O}_{2} \mathrm{Si}$ & 2260 & $374 \quad(6)$ & $\begin{array}{l}73(100), 105(25), 213(50), \\
256(35), 257(22), 331(1), 359(7)\end{array}$ \\
\hline Unknown & $\mathrm{C}_{23} \mathrm{H}_{38} \mathrm{O}_{3} \mathrm{Si}$ & 146 & $390 \quad(3)$ & $\begin{array}{l}73(100), 175(45), 255(18) \\
273(38), 300(3), 375(7)\end{array}$ \\
\hline TMS-oxykaurene (I) & $\mathrm{C}_{23} \mathrm{H}_{40} \mathrm{OSi}$ & 175 & $360 \quad(21)$ & $\begin{array}{l}73(100), 108(95), 119(70) \\
134(50), 229(22), 255(18) \\
270(14), 345(6)\end{array}$ \\
\hline Stigmasterol - TMS (S) & $\mathrm{C}_{32} \mathrm{H}_{56} \mathrm{OSi}$ & 12 & $484 \quad(15)$ & $\begin{array}{l}83(100), 129(60), 255(30), 355(9), \\
379(7), 394(18), 469(2)\end{array}$ \\
\hline$\beta$-Sitosterol-TMS (S) & $\mathrm{C}_{32} \mathrm{H}_{58} \mathrm{OSi}$ & 30 & $486 \quad(24)$ & $\begin{array}{l}129(100), 255(18), 357(40) \\
381(17), 396(41), 471(4)\end{array}$ \\
\hline
\end{tabular}

* Reported as analyzed, $\mathrm{S}=$ matches with mass spectrum of standard, I = interpretation of mass spectrometric fragmentation pattern.

+ Given as microgram per gram of dry weight of the plant material.

$¥$ Given as $m / z$ with relative intensity in parentheses. 
Table III. Compound specific carbon isotope data for lipid hydrocarbons from Laretia compacta.

\begin{tabular}{lll}
\hline Compound Name & Composition & $\delta^{13} \mathrm{C}(\% \circ)^{*}$ \\
\hline Kaur-16-ene & $\mathrm{C}_{20} \mathrm{H}_{32}$ & $-25.2 \pm 0.9$ \\
Hibaene & $\mathrm{C}_{20} \mathrm{H}_{32}$ & $-23.8 \pm 0.7$ \\
Tetracyclic diterpene & $\mathrm{C}_{20} \mathrm{H}_{32}$ & $-24.7 \pm 1.1$ \\
$n$-Heneicosane & $\mathrm{C}_{21} \mathrm{H}_{44}$ & $-19.6 \pm 1.6$ \\
$n$-Tricosane & $\mathrm{C}_{23} \mathrm{H}_{48}$ & $-19.2 \pm 0.4$ \\
$n$-Pentacosane & $\mathrm{C}_{25} \mathrm{H}_{52}$ & $-19.8 \pm 1.2$ \\
mean diterpenes & & $-24.6 \pm 0.7$ \\
mean alkanes & & $-19.5 \pm 0.4$ \\
\hline
\end{tabular}

* Data reported in per mil vs. PDB (Pee Dee Belemnite) standard, mean of $n=3$.

Collister J. W., Rieley G., Stern B., Eglinton G. and Fry B. (1994), Compound-specific $\delta^{13} \mathrm{C}$ analyses of leaf lipids from plants with differing carbon dioxide metabolisms. Organic Geochemistry 21, 619-627.

Freeman K. H. (1991), The carbon isotopic composition of individual compounds from ancient and modern depositional environments, Ph.D. dissertation, Indiana University, $146 \mathrm{pp}$.

Hayes J. M., Freeman K. H., Popp B. N. and Hoham C. H. (1990), Compound specific isotope analyses, a novel tool for reconstruction of ancient biogeochemical processes. In: Advances in Organic Geochemistry 1989 (Durand B. and Behar F., eds.). Organic Geochemistry 16, 1115-1128.

Grimalt J. O., Alexander G., Hazai I. and Mink G. (1990), The isomerization and aromatization of $16 \alpha(\mathrm{H})$-phyllocladane in sedimentary environments. Naturwissenschaften 77, 534-536.

Johns R. B., ed. (1986), Biological Markers in the Sedimentary Record. Elsevier Science Publishers, Amsterdam.

Muñoz C. (1966), Sinopsis de la flora chilena. 2nd ed., Ed. de la Universidad de Chile, Santiago, 500 pp.

Schoell M., McCaffrey M. A., Fago F. J. and Moldowan J. M. (1992), Carbon isotopic composition of 28,30bisnorhopanes and other biological markers in a Monterey crude oil. Geochim. Cosmochim. Acta 56, $1391-1399$.

Simoneit B. R. T. (1978), The organic chemistry of marine sediments. In: Chemical Oceanography, 2 nd ed. minor phyllocladenes) with some mono- and sesquiterpenoids. The $\delta^{13} \mathrm{C}$ data of individual $n$-alkanes place this species in the $\mathrm{C}_{4}$ plant group.

\section{Acknowledgement}

We are grateful to Dr. M. Schoell and the Chevron Petroleum Technology Company for the CSIA data and thank R. F. Dias and M. Haught for technical assistance. B. R. T. S. gratefully acknowledges the Dirección General de Investigación Científica y Enseñanza Superior of Spain for a visiting investigator grant (SAB 95-0322).

(J. P. Riley and R. Chester, eds.). Academic Press, New York, vol. 7, pp. 233-311.

Simoneit B. R. T. (1989), Organic matter of the troposphere - V: Application of molecular marker analysis to biogenic emissions into the troposphere for source reconciliations. J. Atmospheric Chem. 8, 251-275.

Simoneit B. R. T. and Mazurek M. A. (1982), Organic matter of the troposphere - II. Natural background of biogenic lipid matter in aerosols over the rural western United States. Atmospheric Environment 16, $2139-2159$.

Simoneit B. R. T., Halpern, H. I. and Didyk, B. M. (1980), Lipid productivity of a high Andean lake. In: Biogeochemistry of Ancient and Modern Environments (P. A. Trudinger, M. R. Walter and B. J. Ralph, eds.) Australian Acad. Sci., Canberra, pp. 201-210.

Simoneit B. R. T., Schoell M., Dias R. F. and Radler de Aquino Neto F. (1993), Unusual carbon isotope compositions of biomarker hydrocarbons in a Permian tasmanite. Geochim. Cosmochim. Acta 57, 42054211.

Smith B. N. and Epstein S. (1971), Two categories of ${ }^{13} \mathrm{C} /$ ${ }^{12} \mathrm{C}$ ratios for higher plants. Plant Physiol. 47, 380384.

Suárez Contreras I. (1935), Contribución al estudio Botánico y Químico de la Laretia compacta Phil. (Llareta). Universidad de Chile, Facultad de Biología y Ciencias Médicas, Memoria, 28 pp.

Wickens G. E. (1995), Llareta (Azorella compacta, Umbelliferae): A review. Economic Botany 49, 207-212. 